\title{
Construction of Agricultural E-commerce Platform in China
}

\author{
Wu Yanyan \\ School of computer and information engineering \\ Harbin University of Commerce \\ Harbin, China \\ wyyhrb@163.com
}

\begin{abstract}
The decentralized management of agricultural production is inconsistent with the big market and circulation in China. Agricultural e-commerce platform can help connecting supply and demand better. The paper analyzes the application and characteristics of agricultural e-commerce in China and points out that the construction of agricultural ecommerce platform is the first step in the development of agricultural e-commerce. Combined with the situation and characteristics of the Chinese agriculture, several construction frames are given for the development of agricultural e-commerce platform. For example, big enterprises build third party agricultural public trade platform under the guide of the government based on market operation. And then local government may lead to construct collaborative agricultural e-commerce platform to integrate the local resources. At the same time, some strategies should also be implemented in order to realize the sustainable development of the platform, especially the application of mobile e-commerce.
\end{abstract}

Keywords: agriculture, E-commerce, Third-party e-commerce, collaborative $e$ commerce

\section{Introduction}

With the quick development of information technology, e-commerce has been defined as "...the process of buying, selling, or exchanging products, services, and information via computer networks" (Turban et al., 2004). The meaning refers to all works related with the sharing of supply and demand information, maintaining relationships, and conducting transactions through networks (Zwass, 1996). Its emergence is believed to transform the conduct and structure of business (Kauffman \& Waiden, 2001) [1]. For agricultural firms including producers, processors, retailers, wholesalers, e-commerce can serve as an additional trade and marketing channel. Because agricultural e-commerce platform can provide good opportunity to extend supply chain (Henderson, 1981). Generally, agricultural e-commerce may play an important role for agricultural enterprises, especially providing them an alternative communication medium with business partners and further developing their business activities through Internet [2]. The types of agricultural e-commerce platform can be distinguished in three major categories (Wilson, 2001): e-markets for the outputs of farms, namely B2C e-commerce; e-markets for the production factors and inputs of farms, namely B2B e-commerce; e-markets of services by third parties, namely professional e-commerce platform [3]. It is important to note that agricultural e-markets demonstrate different degrees of e-commerce adoption. Agricultural e-commerce is in rapid development, and many agricultural enterprises are actively adopting e-commerce, especially in China. 


\section{E-commerce Adoption in China Agriculture}

Agriculture is one of the basic industries that supports all activities and pursuits of humankind. It represents an important percentage of GDP in China, ensures and creates jobs as well. With the development of information technology, agriculture also is involved in the trend. Agriculture e-commerce has become the most popular issue.

China is an agricultural country, agriculture website is developing quickly. Many provinces generally not only have established "agricultural information website", but also have produced some large online market, e.g. "Fuzhou peak", "Nanjing BaiYunting" etc. Online business varieties also expands from agricultural food, fertilizer to agricultural chemicals, special local product, flowers, tea, fresh fruit and so on, which created a platform for the rural economic development.

At present, there are more than 2, 000 rural e-commerce sites in China, and the agriculture web site for more than 10, 000. The agriculture websites issue much information about vegetables, fruits, trees, livestock and poultry, aquaculture and other agricultural supply and demand information and related economic, investment information. The agricultural e-commerce websites have played an important role to prompt agricultural products circulation, improve agricultural efficiency and farmers' income. Some websites have produce great influence such as China's agricultural science and technology information network (www.caas.net), China agricultural information network (www.agri.gov.cn), seed group co., LTD. (www.chinaseeds.com.cn), the north China seed industry information center (www.northseed.com.cn) and so on. This shows that China's agricultural e-commerce is into a period of rapid development. Due to December 2013, the scale of rural Internet users reached 177 million, and the rural population accounted for $28.6 \%$ of Internet users in China. China's rural Internet penetration rate reached $27.5 \%$, and it continued to increase. All of these have provided good basis for the development of agricultural e-commerce of China [4].

\section{Types of Agricultural E-commerce in China}

According to McKertich (2004), the nature of the agricultural sector has shaped essentially two types of e-marketplaces that address the needs of the agricultural supply chain, from livestock, dairy products, fruit and vegetables, or aquaculture, distribution, and retailing. One of them is online exchange which is typically a digital marketplace. The other one is e-marketplace, which usually provides management services to support business and generally attracts the retail and processing end of the supply chain, as the buying process is more structured and less dependent on perishability of goods [5]. In China, types of agricultural e-commerce may include as follows.

\subsection{Professional Agricultural e-commerce Websites}

This type agricultural e-commerce mainly provides agricultural product supply and demand information services, agricultural products trading as a supplement and mainly facing a locality. So it can be seen as an information release platform. This type website is constructed by information and technology companies and supported by the local government which service for the local agriculture business and peasant.

For example, the websites including www.3nong.com, www.nongshang168.com, www.cnhnb.com and www.b2bagri.com.cn are built by network information and technological company and local or national agriculture department are information service platform. They provide information services, logistics services as an agricultural products e-commerce platform, but cannot provide online exchange.

ZhongNong network (www.ap88.com) so-called the biggest agricultural products ecommerce based on traceability, provides agricultural products price index, wholesale, 
food traceability etc. agricultural products information services. But its services are mainly facing Shenzhen, Guangdong not the whole nation.

Heilongjiang agriculture information website (www.hljagri.gov.cn) is hosted by Heilongiiang government, providing agricultural products information in Heilongiiang province. In the whole, this type agriculture e-commerce has obviously regional characteristic, and mainly provides information of supply and demand to speed up the transaction.

\subsection{Agricultural Products Transaction based on Comprehensive B2B Platform.}

Some famous B2B platform have all provide agricultural products transaction, such as Alibaba (www.1688.com) provides food and agriculture plate subdivided into snack market, fresh fruit market, rice grain and oil goods, drinks and tea market, maternal and infant health market. Huicong website (www.HC360.com) includes feed market, seedling market, food market. The trading volume of this type of agricultural e-commerce is less than other products, and with little attention.

\subsection{Professional Agricultural Products B2C Platform}

This e-commerce has been developing quickly. For example, www.benlai.com, www.sfbest.com, www.youcai.com, and www.tootoo.cn are the professional fresh agricultural food platform. And Benlai network provides cold chain logistics in 8 hours and it is famous for the sale of "Chu orange". So it is a better agricultural products platform in China, but it has a limited distribution business scope. And the development of SFbest is based on the SF express, but it has no use well its distribution network. And the development of Youcai and Tootoo websites is not well. Therefore, the B2C platform of agricultural products is developing difficult.

\section{Characteristics of Chinese Agricultural e-commerce}

Comprehensively, at present, we can see that agricultural e-commerce in China has faced big barrier. It is mainly reflected from the following aspects:

\subsection{Obvious Regional Characteristics}

China is a large country and the land area is big. There are huge types and quantity of agricultural products. At the same time, due to agricultural products have higher logistics requirements. The sale of agricultural products is limited in a small region. Therefore, China's agricultural e-commerce market has obvious regional characteristics.

\subsection{Mainly Provide Agricultural Prices Information Service}

Most agricultural e-commerce has not yet been formed sales model, and they mainly provide the information service such as prices, production and demand. Online payment, online marketing and other business model have not been widely used. A few fresh electric business enterprises are exploring online direct marketing model.

\subsection{Service Object Mainly Facing to the Final Agricultural Products}

The main purpose of agricultural e-commerce in China is still in use of network to expand sales channels. And the sales object is the final consumer. So, the development of electronic commerce activity is to meet the needs of final consumers. And there is less ecommerce for the purpose of agricultural reprocessing. As a result, it limited the scale of agricultural e-commerce. 


\subsection{Lack of Large-scale Agricultural e-commerce Enterprises}

Agricultural e-commerce development in China more depends on the third-party ecommerce platform. As a result, the market structure is small and loose. There are many small and medium enterprises in the competition stage, and there has not yet formed a scale of professional electric business enterprise of agricultural products, especially the lack of large-scale agricultural enterprise websites. Moreover, agricultural e-commerce business model is similar. And most of the business is in the exploratory stage, has not formed a fixed operating mode or operating characteristics, and most enterprises have limited scale and poor profitability.

\subsection{Logistics Distribution is the Bottleneck and Lack of Offline Experience Store}

Agricultural products have a short shelf life and perishable, so cold chain logistics in agricultural products distribution is required [6]. But at present, except a few professional fresh agricultural products e-commerce enterprises have a certain range of cold chain logistics capability. Most e-commerce companies don't have the requirement of cold chain logistics, which leads to severe constraints for the sale of agricultural products. In addition to, agricultural products are less standardized goods. And consumers' preference of agricultural products is different. So building experience shop and community distribution network is the important basis for the development of e-commerce of agricultural products.

\section{Construction Schemes for China Agricultural e-commerce Platform}

Under the condition of agricultural enterprises and agricultural e-commerce in China, the paper puts forward several agricultural e-commerce platform construction plans, and analyzes them in detail.

\subsection{Enterprise's Own e-commerce Platform}

By changing the management and operation mode, agricultural enterprises can establish their own e-commerce platform, through increasing investment in information infrastructure construction, building internal network, as shown in Figure 1.

The construction scheme is suitable for the large agricultural companies, which has relatively developed information network, good information infrastructure and wide customer base [7]. This type platform should have the following functions: relevant policies and regulations, information consulting, online product information and the query, online business negotiation, online trading, commodity distribution, after-sales service and related information etc.

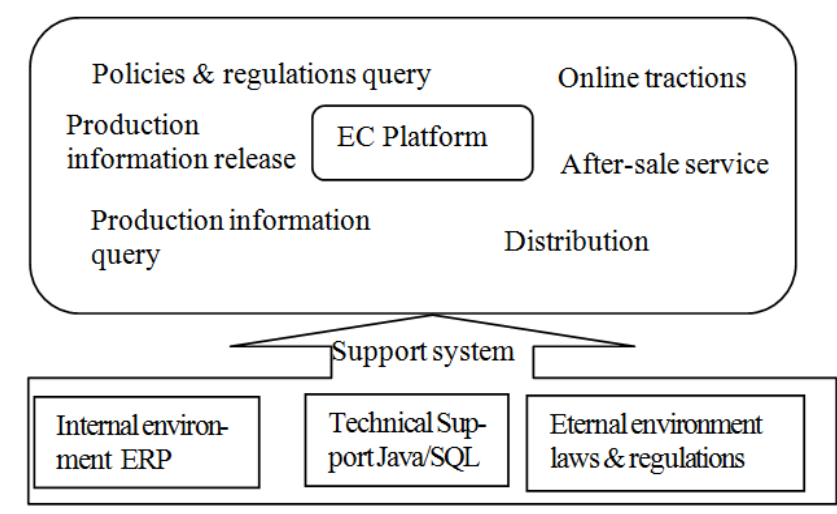

Figure 1. Frame of Enterprises' Own e-commerce Platform 


\subsection{Based on Third-party e-commerce Public Platform}

For the present situation of "small farmers and big market" in Chinese agriculture, the e-commerce platform need to solve the problems such as small scale, weak infrastructure, lack of effective connection between enterprises and markets, especially for the small and medium-sized agricultural entities [8]. In addition, high transaction costs, inventory pressure, low level of specialization and scale problems are also the main problems. The third parties e-commerce platform can provide the public platform to carry out the agricultural e-commerce activity suitable for SMEs, as shown in Figure 2.

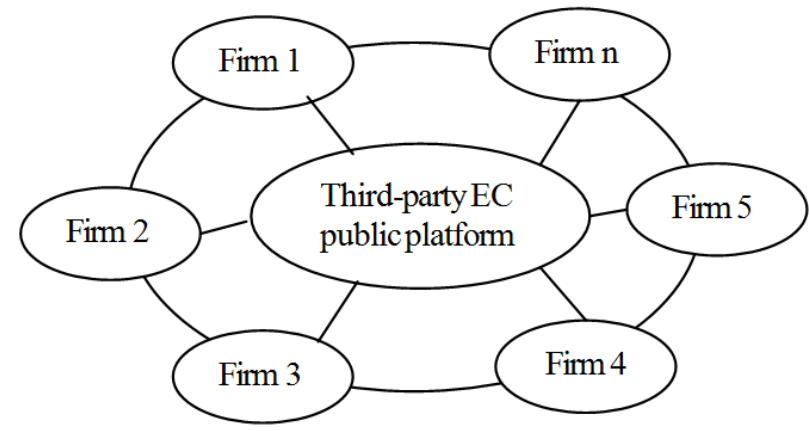

Figure 2. Frame of Third-party e-commerce Public Platform

The construction scheme is suitable for small and medium-sized agricultural enterprises. They rely on third parties to provide the public platform of e-commerce activities, which can implement electronic commerce, and join the third-party ecommerce platform with lower cost and enjoy professional information services and value-added services [9]. It may increase opportunities for the development of the agricultural production and business operation. And the third-party e-commerce providers should utilize the commercial Web site running mechanism to set up an electronic commerce system which is cross-industry, open and service for the whole business process in the true sense [10]. Moreover, after several years of exploration and management, third-party e-commerce has been relatively mature. And at present, this ecommerce application mode is generally used in Chinese small and medium-sized agricultural business.

The most basic function of the third party e-commerce mode is to provide information intermediary services for online transactions between buyers and sellers. So it should have the following functions: first of all, buyers and sellers can release their purchasing or sales information on the Internet and select potential suppliers or customers according to the published information. Second, it should provide additional information service such as industry information and sent buy and sell information to the customer regularly. Third, it should provide services matching trade, such as online contracts, online payment, etc. Fourth, provide customer management functions, namely, online transaction management, including the hosting service for the enterprise contract, transaction records, customer information.

Third-party e-business pattern has changed the traditional way of working and the inherent thinking mode, which is more easily accepted by agricultural enterprises. Many agricultural production and business operation entities gathering on a third party platform can bring advantage of the new procurement, planning and decision-making for ecommerce alliance members. Third-party e-commerce model is effective to promote the development of agricultural e-commerce in China. With the support of social forces and the government, the third party agricultural e-commerce platform can provide more effective e-commerce support for more agricultural entities. 


\subsection{Collaborative e-commerce Platform}

Collaborative e-commerce is mainly based on the B2B e-commerce mode. And its basic idea is put forward by Gartner Group in 1999. It utilizes information network technology, through integrated business platform to provide business integration, information sharing and collaborative work for the enterprise and its partners. It can realize information collaboration, internal and external coordination to develop an effective value chain [11]. According to the basic idea of collaborative e-commerce, agricultural entities can be combined and in accordance with the system theory and synergetics they can build the e-commerce platform composed by "supply, production and sales" chain and integration of modern management techniques (CRM, SCM, etc.,) which can build a virtual integration market. The frame structure is shown in Figure 3.

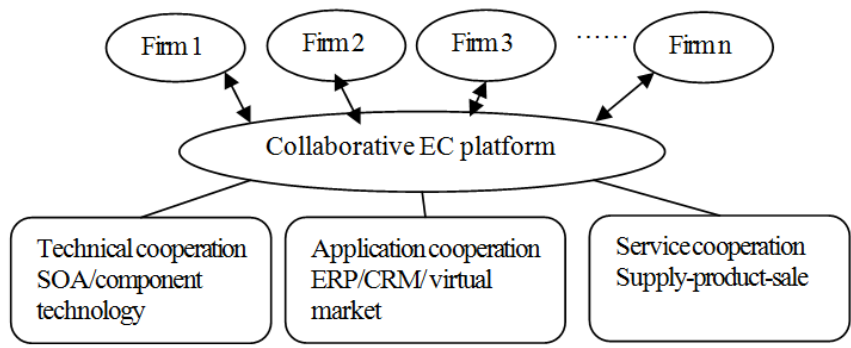

Figure 3. Frame of Collaborative e-commerce Platform

Collaborative e-commerce will effectively reduce the development cost of agricultural e-commerce platform. Using the collaborative e-commerce can make enterprises expand in the whole supply chain even global supply chain, and make highly flexible, rapid response virtual enterprises. And it may realize the services business model and business integration for the mining, processing, design, production, distribution, transportation, and marketing in global.

Collaborative e-commerce should have collaboration in technology, application and service. Technology collaboration refers to using software component technology, such as middleware technology and service-oriented architecture (SOA) technology to make the platform has good integration, scalability, portability and consistency to ensure the sharing of information resources. Application collaboration refers to utilize SCM, CRM, and other modern management technology, make a huge virtual market. Service collaboration is to create a service chain of supply, production, sales service by enterprise alliance.

\subsection{International Agricultural e-commerce Platform}

Establishing international e-commerce platform with characteristics is one of the effective means to exploit the international market, which can make full use of the Internet convenience and advantage. It is also an effective way to show enterprise image when agricultural enterprises participate in international competition. As shown in Figure 4. 


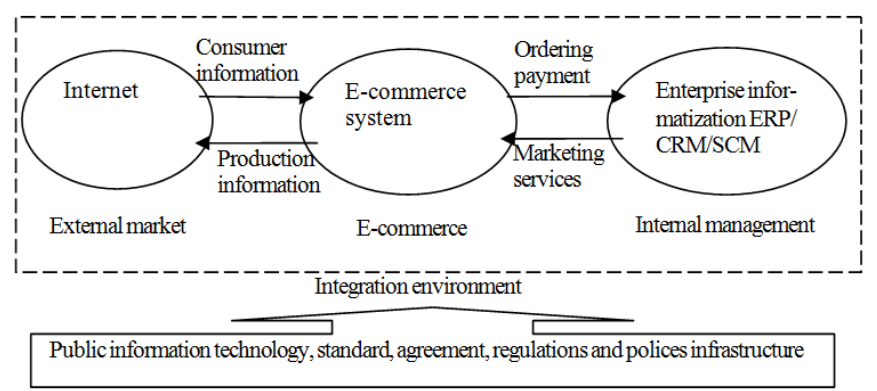

Figure 4. Frame of International e-commerce Platform

This kind of platform is suitable for the enterprises or enterprises alliance. They want to explore international market, have the international market competitiveness, and the production of agricultural products has won the international quality certification [12]. The platform should have the following functions: product information release system, online customer consultation system, the international order query system, customer feedback system, customer service centers, investment opportunities, product knowledge, FAQ, a global sales network, the global procurement system, etc. International ecommerce platform should achieve the goals including: international customers can order or feedback information directly through the platform, to release the latest product information and development of the enterprise and to collect the latest information reference, more importantly, it should realize the online trading of international trade, global sourcing and distribution and so on, eventually reduce business costs, improve work efficiency, improve the competitiveness.

\section{Construction Strategies for Chinese Agricultural e-commerce Platform}

Establishing agricultural e-commerce platform is the first step, in order to build agricultural e-commerce platform, promote the rapid development of agricultural ecommerce, the following several aspects should be followed.

\subsection{Choose the Proper Agricultural e-commerce Platform Construction Scheme}

For few large agricultural enterprises with better information infrastructure, they can choose to build their own e-commerce platform, and through the Internet to realize the internationalization of e-commerce. For most small and medium enterprises, they can rely on third-party e-commerce platform to implement electronic commerce. And for the enterprise alliance with closely business links and intensive management they can build collaborative e-commerce platform by the method of integration. And for enterprises or enterprise alliance with strong market competitiveness and trying to develop the global market, they can set up international e-commerce platform, participating in international competition.

\subsection{Strengthen the Promotion of Agricultural e-commerce Platform}

No matter adopting what kind of solution to set up e-commerce platform, propaganda and promotion must be done which can expand the visits and win the attention and recognition [13]. At that time, we should pay attention to: the platform design should have agricultural characteristics; it must have a good safety and interactive; in the public media to release website information; to publish online advertising, set up links, send an email to potential customers; to set up their own position in search engines to let potential customers find themselves. 


\subsection{Perfect Functions of Agricultural e-commerce Platform}

At present, a lot of agricultural e-commerce platform only have static information, this is obviously not enough. And a good agricultural e-commerce platform must provide latest information quickly, and at the same time, it also should provide the following functions: product information, online customer consultation, online payment transaction, logistics, customer service, investment opportunities etc. Only a fully functional ecommerce platform can win more business opportunities.

\subsection{Develop Mobile Agricultural e-commerce}

Mobile client access to the electronic commerce has become the new hot spot and tendency of the development of the electronic commerce. In several online equipment, rural Internet users more choose mobile phone to access to the Internet, the proportion of using mobile phone is higher than that of using the rest of the equipment are all below the town. As of December 2013, in rural areas the proportion of Internet users use mobile Internet has reached $84.6 \%, 5 \%$ higher than that in cities and towns [14]. Mobile Internet with the advantage of low cost, easy to operate has been becoming the mainstream of access to the Internet. Therefore, agricultural e-commerce platform should also actively launch mobile e-commerce client, speed up the popularization of mobile agricultural ecommerce.

\section{Conclusions}

E-commerce has just been developing quickly in China. Agricultural e-commerce is also facing the huge opportunity, and serious challenges. There are still many questions to face and many difficulties need to be solved. The construction of agricultural e-commerce platform can only build from the fact and only in this way the sales market of agricultural products can be opened. Only break the regional limitation, national boundaries and participate in international competition, Chinese agriculture enterprises can success in the global competition. Therefore, the discussion of the construction of agricultural ecommerce platform may have a reference for the development of agricultural e-commerce in China.

\section{Acknowledgements}

The paper is supported by Heilongiiang Philosophy and Social Science Fund NO.14B008.

\section{References}

[1] N. Manouselis, A. Konstantas, N. Palavitsinis,C. Costopoulou and A. B. Sideridis, "A Survey of Greek Agricultural E-Markets”, Agricultural Economics Review, vol. 10, no. 1, (2009), pp. 97-112.

[2] E. Cloete and M. Doens, "B2B e-Marketplace Adoption in South African Agriculture", Information Technology for Development, vol. 14 , no. 3, (2008), pp. 184-196.

[3] S. D. Zapata, C. E. Carpio, O. Isengildina-Massa and R. Dave Lamie, "The Economic Impact of Services Provided by an Electronic Trade Platform: The Case of MarketMaker”, Journal of Agricultural and Resource Economics, vol. 38, no. 3, (2013), pp. 359-378.

[4] "China internet network development statistic report", (2014), http://www.cnnic.net/hlwfzyj/ hlwxzbg/.

[5] Rolf A. E. Mueller, "E-Commerce and Entrepreneurship in Agricultural Markets", American Journal of Agricultural Economics, vol. 83, vol. 5, (2001), pp. 1243-1249.

[6] D. Lv and Q. Zhou, "Development model of agricultural E-commerce in the context of social commerce", Journal of Chemical and Pharmaceutical Research, vol. 6, no. 7, (2014), pp. 1341-1345.

[7] J. Henderson, F. Dooley and J. Akridge, "Inernet and E-commerce Adoption by agricultural input firms", Review of Agricultural Econmics, vol. 26, no. 4, (2003), pp. 505-520.

[8] F. Montealegre, S. Thompson, and J. S. Eales, "An Empirical Analysis of the Determinants of Success of Food and Agribusiness E-Commerce Firms", International Food and Agribusiness Management Review, vol. 10, (2007), pp. 61-81. 
[9] E. Brynjolfsson and L. M. Hitt, "Beyond Computation: Information Technology, Organizational Transformation and Business Performance", J.Econ. Perspective, vol. 14, (2000), pp. 23-48.

[10] Zoujin, "Analyze on Chinese agricultural third-party e-commerce mode", Business Times, vol. 5, (2007), pp. 24-25.

[11] C. Subramaniam and M. J. Shaw, "A Study of the Value and Impact of B2B E-Commerce: The Case of Web-Based Procurement", International Journal of Electronic Commerce, vol. 6, (2002), pp. 19-40.

[12] J. C. Whitehead, T. J. Hoban and W. B. Clifford, "Willingness to Pay for Agricultural Research and Extension Programs", Journal of Agricultural and Applied Economics, vol. 33, pp. 91-101, (2001).

[13] A. L. Fruhling and L. A. Digman, "The Impact of Electronic Commerce on Business-Level Strategies", Journal of Electronic Commerce Research, vol. 1, (2000), pp. 13-22.

[14] “China mobile internet report", (2014), http://www.cnnic.net/hlwfzyj/hlwxzbg/ 
International Journal of $u-$ and $e-$ Service, Science and Technology Vol.8, No.1 (2015) 